\title{
Oxygen-17-induced Proton Relaxation Rates for Alcohols and
}

\author{
Alcohol Solutions \\ Thomas C. Farrar ${ }^{\mathrm{a}}$, Mark A. Wendt ${ }^{\mathrm{a}}$, and M.D. Zeidler \\ ${ }^{\mathrm{a}}$ Department of Chemistry, University of Wisconsin, 1101 University Avenue, Madison, \\ 53706 WI, USA \\ ${ }^{\mathrm{b}}$ Institut für Physikalische Chemie der RWTH, Templergraben 59, \\ D-52056 Aachen, Germany
}

O uso de amostras de álcoois enriquecidas com ${ }^{17} \mathrm{O}$, para medir o tempo de correlação do vetor internuclear $\mathrm{OH}$ funciona bem quando o próton da hidroxila sofre uma troca rápida. Para álcoois tais como metanol e etanol, a taxa de troca da hidroxila para amostras puras é relativamente lenta, mesmo à temperatura ambiente, podendo resultar em erros sistemáticos significativos se efeitos de troca lenta não forem considerados. Para trocas lentas do próton da hidroxila, ${ }^{17} \mathrm{OH}$, o sinal é uma função relativamente complexa da razão de troca química do próton da hidroxila, do acoplamento de spin $\mathrm{OH}$ (cerca de $80 \mathrm{~Hz}$ para álcoois e água) e do tempo de relaxação para o oxigênio. A largura de linha do $\mathrm{OH}$ pode tornar-se tão grande, devido à relaxação escalar com o núcleo de oxigênio, que o sinal torna-se muito difícil de detectar. Para etanol puro enriquecido com ${ }^{17} \mathrm{O}$, à temperatura ambiente, o tempo de relaxação do oxigênio é de aproximadamente 3,0 ms e a largura de linha do próton da hidroxila é maior do que $1000 \mathrm{~Hz}$.

The use of ${ }^{17} \mathrm{O}$ enriched samples of alcohols to measure the correlation time of the $\mathrm{OH}$ internuclear vector works well when the hydroxyl proton exchanges rapidly. For alcohols such as methanol and ethanol the hydroxyl exchange rate for neat samples is relatively slow even at room temperature and significant systematic errors result if slow exchange effects are not considered. For slow exchange the hydroxyl proton, ${ }^{17} \mathrm{OH}$, signal is a relatively complex function of the chemical exchange rate of the hydroxyl proton, the $\mathrm{OH}$ spin coupling (about $80 \mathrm{~Hz}$ for alcohols and water) and the relaxation time for the oxygen. The $\mathrm{OH}$ linewidth can become so large due to scalar relaxation with the rapidly relaxing oxygen nucleus that the signal becomes very difficult to detect. For neat ${ }^{17} \mathrm{O}$ enriched ethanol at room temperature the oxygen relaxation time is about $3.0 \mathrm{~ms}$ and the hydroxyl proton linewidth is over $1000 \mathrm{~Hz}$.

Keywords: oxygen-17, proton, relaxation time, NMR line width, exchange rate, quadrupole coupling

\section{Introduction}

A number of recent investigations have reported molecular correlation times for water, simple alcohols and binary solutions of alcohols that are based on the measurement of proton spin lattice relaxation times of oxygen-17 enriched samples $^{1-5}$. For protonated samples the spin-lattice relaxation rate, $R_{1}$, for protons interacting with other protons is given by the dipolar relaxation equation:

$$
\begin{aligned}
R_{l}(\mathrm{H})=\left(\frac{\mu_{0}^{2}}{40 \pi^{2}}\right) \frac{\gamma_{H}^{4} \hbar^{2} I(I+1)}{r_{H H}^{6}} & \left(\frac{\tau_{c}}{1+\omega_{0}^{2} \tau_{c}^{2}}+\right. \\
& \left.\frac{4 \tau_{\mathrm{c}}}{1+4 \omega_{0}^{2} \tau_{\mathrm{c}}^{2}}\right)
\end{aligned}
$$

The various parameters have the standard meaning. This equation is not very useful for studying the dynamics of the hydroxyl proton because a significant part of the relaxation arises from intermolecular interactions for which 
neither the internuclear distance $r_{H H}$ or the correlation time, $\tau_{\mathrm{c}}$, are well defined. For this reason relaxation time experiments have been carried out for the deuterium nucleus. Deuterium relaxation time experiments are attractive since the deuterium quadrupole coupling constant, $\chi_{D}$, is typically ten times greater than dipolar coupling; consequently, intermolecular interactions can be ignored. For a spin-1 nucleus such as ${ }^{2} \mathrm{H}$ the relaxation rate, $\mathrm{R}_{1}$ is given by:

$$
\begin{gathered}
R_{1}=\frac{1}{T_{1}}=\frac{3 \pi^{2}}{10} \chi_{\mathrm{D}}^{2}\left(1+\frac{\eta^{2}}{3}\right)\left(\frac{\tau_{\mathrm{c}}^{\mathrm{D}}}{1+\omega_{0}^{2}\left(\tau_{\mathrm{c}}^{\mathrm{D}}\right)^{2}}+\right. \\
\left.\frac{4 \tau_{\mathrm{c}}^{\mathrm{D}}}{1+4 \omega_{0}^{2}\left(\tau_{\mathrm{c}}^{\mathrm{D}}\right)^{2}}\right)
\end{gathered}
$$

where $\chi_{D}$ is the deuterium quadrupole coupling constant (qcc) in units of $\mathrm{Hz}, \tau_{c}{ }^{D}$ is the molecular correlation time in seconds, and $\omega_{0}$ is the Larmor frequency. For deuterium nuclei the asymmetry parameter, $\eta$, typically has a value of 0.1 or less and the $\eta^{2} / 3$ term can be justifiably neglected. Until recently it was assumed that $\chi_{D}$ was either close to the solid state value (which can be measured accurately via solid state NMR) or was mid-way between the gas phase value (measured via microwave spectroscopy) and the solid state value. Since gas phase $\chi_{D}$ values for -OD deuteriums are about $300 \mathrm{kHz}$ and the solid state values are about 190 $\mathrm{kHz}$, there was considerable uncertainty in molecular correlation times obtained from deuterium relaxation time measurements.

In 1982 Leyte and coworkers ${ }^{4}$ used oxygen- 17 enriched samples of water to obtain correlation times. The proton chemical exchange rate in water is known to be rapid 9 . If a water sample is enriched with oxygen-17 and the proton exchange is rapid, the relaxation rate $R_{1}$ (total) for all protons in the sample will be given by:

$$
R_{1}(\text { total })=R_{1}(\mathrm{H})+X R_{1}^{H}\left({ }^{17} \mathrm{O}\right)
$$

where $X$ is the mole fraction of $\mathrm{H}_{2}{ }^{17} \mathrm{O}, R_{1}$ (total) is the observed relaxation rate, $R_{1}(\mathrm{H})$ is the relaxation rate arising from both intermolecular and intramolecular proton-proton interactions (see Eq. 1 above), and $R_{1}{ }^{H}\left({ }^{17} \mathrm{O}\right)$ is the proton relaxation arising from the dipolar interaction with the oxygen-17. In the extreme narrowing region $\left(\omega \tau_{\mathrm{c}}<<1\right)$ and $\mathrm{R}_{1}{ }^{\mathrm{H}}\left({ }^{17} \mathrm{O}\right)$ is given by:

$$
R_{1}^{H}\left({ }^{17} O\right)=\left(\frac{\mu_{0}}{4 \pi}\right)^{2} \frac{4 \gamma_{H}^{2} \gamma_{O}^{2} h^{2} S(S+1)}{3 r_{O H}^{6}} \tau_{c}^{O H}
$$

where $S$ is the spin of the oxygen-17 $(\mathrm{S}=5 / 2)$, and $\tau_{c}{ }^{O H}$ is the correlation time for the $\mathrm{OH}$ internuclear vector. If the $\mathrm{OH}$ bond distance is known accurately, then the correlation time can be readily obtained from Eq. 4 above. In practice, several samples are normally used with differing amounts of O-17 enrichment and $R_{1}$ (total) is plotted as a function of $X$; the slope of this plot is $R_{I}{ }^{H}\left({ }^{17} \mathrm{O}\right)$ The parameter $\tau_{c}{ }^{O H}$ in Eq. 4 is the correlation time for the $\mathrm{OH}$ (or OD) internuclear vector. Since the OD internuclear vector is coincident (or nearly so within a degree or two) with the principal axis of the deuterium quadrupole coupling tensor, $\tau_{c}{ }^{O H}$ in Eq. 4 and $\tau_{c}{ }^{D}$ in Eq. 2 must be equal. Given the value for $\tau_{c}{ }^{D}$ and the value for the spin-lattice relaxation time for the OD deuteron, one may now calculate the value of $\chi_{D}$.

This was a clever and innovative idea and with it Leyte and his co-workers were able to obtain the temperature dependence of $\chi_{D}$ in water. This same methodology has been used more recently in an effort to obtain information about the temperature and concentration dependence of $\chi_{D}$ in simple alcohols ${ }^{1,2}$ and in water/DMSO (DMSO $=$ dimethylsulfoxide) mixtures ${ }^{6,7}$. Some of the results of the alcohol work have been very puzzling. For example, the work on methanol ${ }^{1}$ and ethanol ${ }^{2}$ indicated that $\chi_{D}$ for the OD deuteron increased with decreasing temperature and the value near the melting point was higher than that for gas phase samples. This work with O-17 enriched alcohol made the important assumption that the hydroxyl proton exchange rate was fast and consequently all hydroxyl protons felt the presence of the oxygen-17. We report data below which indicate that this assumption is only valid for methanol and ethanol in a limited number of special circumstances.

\section{Results and Discussion}

For binary mixtures of methanol in various solvents, the lifetime of the $\mathrm{OH}$ bond varies as a function of solvent, temperature and concentration; the lower the temperature or concentration, the longer the lifetime. Fig. 1b shows the room temperature proton spectrum of a binary mixture of 1.0 mole percent methanol with 99 mole percent benzene$d_{6}$ (there is a 1 percent proton impurity in the deuterated benzene) and a trace of tetramethylsilane (TMS). The spectrum in Fig. 1b shows TMS (singlet), $\mathrm{OH}$ (quartet), $\mathrm{CH}_{3}$ (doublet) and benzene- $d_{6}$ impurity (singlet) at chemical shift values of approximately 0.0, 0.5, 3.0 and $7.0 \mathrm{ppm}$, respectively. At room temperature, the J-coupling for the $\mathrm{OH}$ and methyl resonances are well resolved up to a concentration of about 2.0 mole percent methanol in benzene. For methanol in dimethyl sulfoxide the fine structure is well resolved up to concentrations of about 15.0 mole percent methanol $^{8}$.

The ${ }^{17} \mathrm{O}$ enriched hydroxyl proton spectra of methanol and ethanol can be rather complex. For neat ${ }^{16} \mathrm{O}$ methanol at room temperature, the proton NMR spectrum consists of two singlets, as shown in Fig. 1a. This is clear indication that the hydroxyl proton exchange is rapid compared to the spin-spin coupling constant, J, between the methyl protons and the hydroxyl proton. However, this spectrum is a 

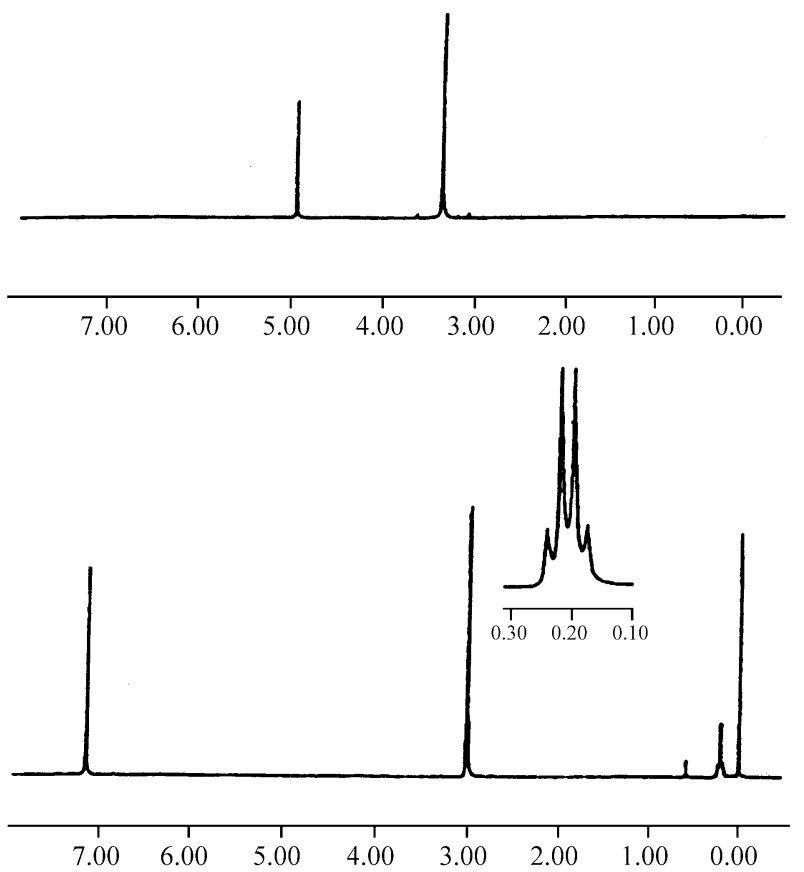

Figure 1. The upper spectrum (1a) is for a room temperature sample of neat methanol. Because of relatively rapid chemical exchange of the hydroxyl protons, no J-coupling is seen between the hydroxyl and methyl protons. Strong hydrogen bonding shifts the $\mathrm{OH}$ resonance line to about $5.0 \mathrm{ppm}$. The lower spectrum (1b) is for a binary mixture of 1.0 mole percent methanol in benzene- $d_{6}$ (see text). For this dilute solution no hydrogen bonding is present and the $\mathrm{OH}$ resonance line is shifted by 5.0 ppm to lower frequency. Since no proton exchange occurs spin coupling between hydroxyl and methyl protons is clearly visible.

sensitive function of temperature and concentration. The spectrum in Fig. 2 was taken at $-20{ }^{\circ} \mathrm{C}$ and clearly shows the spin coupling; the hydroxyl proton is now a quartet and the methyl proton resonance is a doublet. The J-coupling is about $6 \mathrm{~Hz}$ so the exchange rate must be slow compared to $1 / \mathrm{J}$. For $\mathrm{J}=6 \mathrm{~Hz}$, this indicates an $\mathrm{OH}$ bond lifetime that is substantially longer than 200 milliseconds. As the temperature decreases the exchange becomes still slower. If one has a mixed sample of $\mathrm{H}_{3} \mathrm{C}^{17} \mathrm{OH}$ and $\mathrm{H}_{3} \mathrm{C}^{16} \mathrm{OH}$ and the exchange is slow one will observe, at temperatures of $-20^{\circ} \mathrm{C}$ and lower, the doublet and quartet for the $\mathrm{H}_{3} \mathrm{C}^{16} \mathrm{OH}$ molecule. The $\mathrm{H}_{3} \mathrm{C}^{17} \mathrm{OH}$ proton spectrum will be quite different. Since ${ }^{17} \mathrm{O}$ has a spin of $5 / 2$, it will split the $\mathrm{OH}$ proton into six lines and each of these lines will, of course, be further split into quartets by the J-coupling with the methyl protons.

If the proton-proton coupling is well resolved, indicating very slow exchange, the ${ }^{17} \mathrm{OH}$ spin coupling will also be well resolved; the $\mathrm{OH}$ coupling in water and simple alcohols is about $80 \mathrm{~Hz}$. In a 5.0 mole percent binary mixture of ethanol and chloroform, the natural abundance ${ }^{17} \mathrm{O}-\mathrm{NMR}$ spectrum is a well resolved doublet with a splitting of $80.0 \pm 1.0 \mathrm{~Hz}$. The width of the doublet lines is 75.0
Hz. Although for neat ethanol, the ${ }^{17} \mathrm{O}$ spectrum is an unresolved doublet, the line widths can be deduced from oxygen spin lattice relaxation time measurements and the ${ }^{17} \mathrm{O}$ linewidth; the result is a spin coupling of about $80 \mathrm{~Hz}$ and linewidths of about $120 \mathrm{~Hz}$. The oxygen $\mathrm{T}_{1}$ value is about $3.0 \mathrm{~ms}$. The broader proton lines in the neat liquid are due to the significantly shorter ${ }^{17} \mathrm{O}$ relaxation time.

Under conditions of slow chemical exchange there will be separate hydroxyl proton resonance lines for the $\mathrm{H}_{3} \mathrm{C}^{17} \mathrm{OH}$ and $\mathrm{H}_{3} \mathrm{C}^{16} \mathrm{OH}$ molecules. The ${ }^{17} \mathrm{OH}$ proton spectrum will be a sextet of quartets and will span a region of about $500 \mathrm{~Hz}$. The proton lines will be rather broad because they are spin-coupled to $\mathrm{O}-17$ which has a relaxation time at room temperature of about $3.0 \mathrm{~ms}$. If two nuclei, for example I and $\mathrm{S}$, are spin-coupled and nucleus $\mathrm{S}$ has a lifetime that is short compared to $1 /(2 \pi J)$, where $2 \pi J$ is the coupling constant in units of seconds, then the local magnetic field, $2 \pi J S(t) / \gamma_{I}$, produced at nucleus I by nucleus $\mathrm{S}$ fluctuates with a correlation time $\tau_{s}=T_{1}(S)$. In this event, only the average value of the J-coupling is seen and nucleus I does not exhibit the expected multiplet, but a singlet whose line width is a function of the strength of the J-coupling and the lifetime of the $\mathrm{S}$ nucleus. The lifetime of a nucleus I in a given spin-state can be shortened either by chemical exchange or by being coupled to a second nucleus, $\mathrm{S}$, which has a short spin-state lifetime. For the hydroxyl proton ${ }^{17} \mathrm{OH}$ spectrum, $\mathrm{I}=\mathrm{H}$ and $\mathrm{S}={ }^{17} \mathrm{O}$, the linewidths, $\Delta v_{1 / 2}$, of the proton lines are related to the proton spin-spin relaxation rate, $\mathrm{R}_{2}$. In particular, $\Delta \nu_{1 / 2}=1 /\left(\pi \mathrm{T}_{2}\right)=\mathrm{R}_{2} / \pi$, where $\mathrm{R}_{2}$ is given by the well-known scalar coupling relation $^{10}$

$$
R_{2}^{H}=\frac{(2 \pi J)^{2}}{3} S(S+1)\left(\tau_{S}+\frac{\tau_{S}}{1+\left(\omega_{H}-\omega_{S}\right)^{2} \tau_{S}^{2}}\right)
$$

where $S$ is the spin of the oxygen $(S=5 / 2), \tau_{S}$ is the lifetime of the ${ }^{17} \mathrm{O}\left(\tau_{S}=T_{1}\left({ }^{17} \mathrm{O}\right)\right)$, $\mathrm{J}$ is the ${ }^{17} \mathrm{OH}$ spin coupling constant (about $80 \mathrm{~Hz}$ ) and $\omega_{H}$ and $\omega_{S}$ are the NMR resonance frequencies (in units of $\mathrm{s}^{-1}$ ) of the proton and oxygen, respectively. Since $T_{1}\left({ }^{17} \mathrm{O}\right)$ is about $3.0 \mathrm{~ms}$ at room temperature, $\left(\omega_{H}-\omega_{S}\right)^{2} \tau_{S}^{2}<1$ and Eq. 5 becomes

$$
\mathrm{R}_{2}^{\mathrm{H}}=\frac{(2 \pi \mathrm{J})^{2}}{3} \cdot \frac{35}{4} \cdot 2 \tau_{\mathrm{S}}
$$

For $J \cong 80 \mathrm{~Hz}$, and $\tau_{S}=T_{l}\left({ }^{17} \mathrm{O}\right)=0.003 \mathrm{~s}$, we have $R_{2}{ }^{H}$ $\cong 4,000 \mathrm{~s}^{-1}$ and the proton line width $\Delta v_{1 / 2} \cong 1000 \mathrm{~Hz}$. The final proton spectrum, then, is a set of six unresolved lines each with a width of about $1000 \mathrm{~Hz}$ and a separation of about $80 \mathrm{~Hz}$; the ${ }^{17} \mathrm{OH}$ proton will be so broad that it will disappear into the noise level of the spectrum. Since the total integrated line intensity is spread over such a wide range, the signal will be very difficult, if not impossible, to observe. The fact that $T_{1}$ for the $\mathrm{OH}$ proton is relatively long 


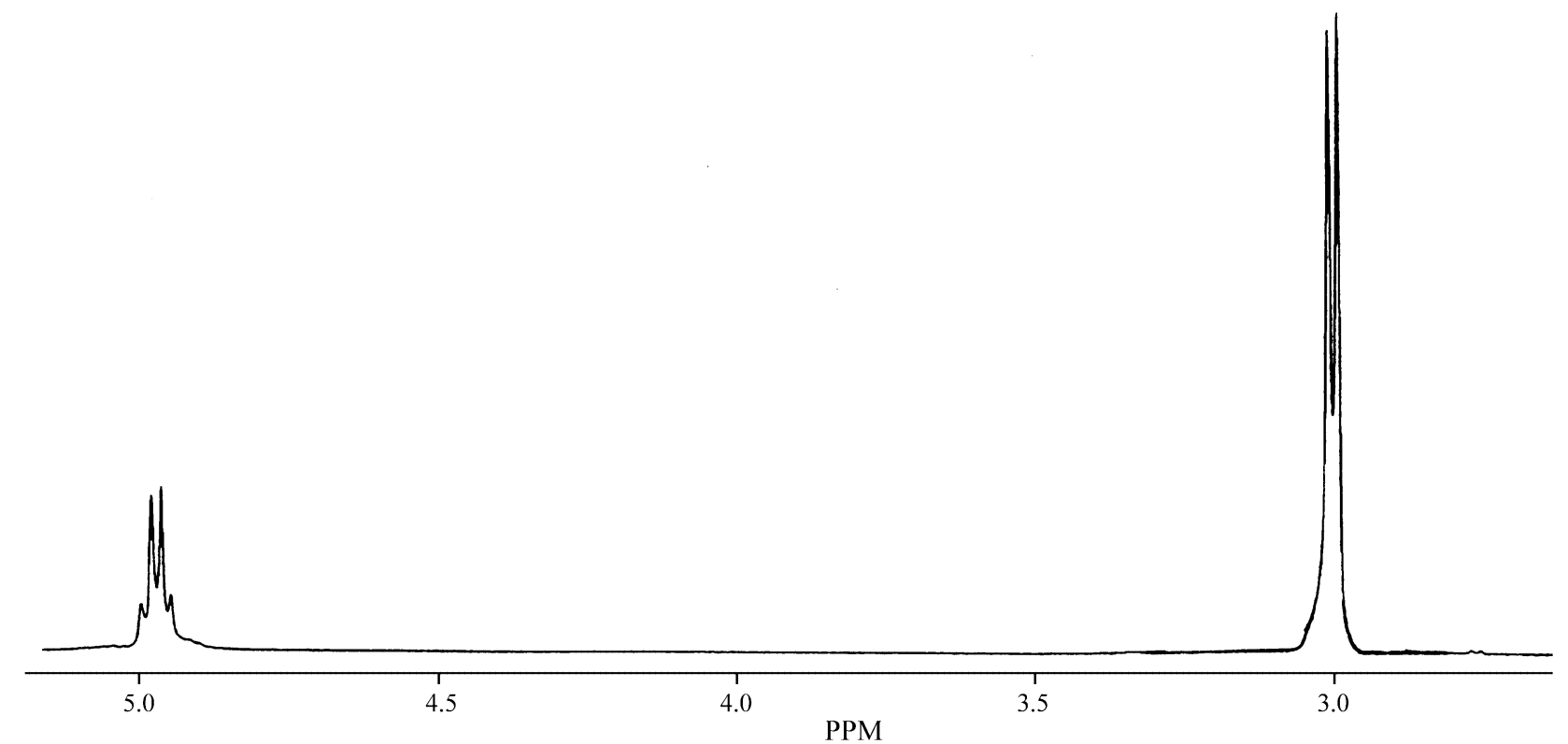

Figure 2. The proton NMR spectrum of neat methanol at $-20^{\circ} \mathrm{C}$. At this lower temperature the proton exchange is very slow and spin coupling is resolved.

while $T_{2}$ is quite short exacerbates the problem of observing the $\mathrm{OH}$ resonance line. Figure 3 shows a simulated room temperature spectrum of an $80 / 20$ mixture of $\mathrm{H}_{3} \mathrm{C}^{17} \mathrm{OH} / \mathrm{H}_{3} \mathrm{C}^{16} \mathrm{OH}$, using a value of $80.0 \mathrm{~Hz}$ for the $\mathrm{OH}$ spin coupling constant, and hydroxyl proton line widths of $30 \mathrm{~Hz}$ and $0.5 \mathrm{~Hz}$ for the $\mathrm{CH}_{3}{ }^{17} \mathrm{OH}$ and $\mathrm{CH}_{3}{ }^{16} \mathrm{OH}$, respectively. As can be seen, even for this mild line broadening (the actual line broadening is a factor or 30 greater at room temperature) the signal from the oxygen-17 enriched hydroxyl protons is almost lost in the noise. For the greater line widths occuring in a typical sample, the oxygen-17 enriched hydroxyl proton signal is completely lost in the noise.

As the temperature of the sample decreases the dipolar contributions to the proton $T_{1}$ and $T_{2}$ will increase and both relaxation times will become shorter in the usual Arrhenius fashion. The proton exchange rate will also decrease, that is, the lifetime of the $\mathrm{OH}$ bond will increase. Decreasing temperature will also lead to a substantial decrease in the ${ }^{7} \mathrm{O}$ relaxation times. For example, the $T_{1}$ minimum $\left(\omega_{0} \tau_{c} \cong\right.$ 1) in ${ }^{17} \mathrm{O}$ enriched ethanol occurs at a temperature of about $-120{ }^{\circ} \mathrm{C}$. At this temperature $T_{1}\left({ }^{17} \mathrm{O} \cong 5 \times 10^{-5} \mathrm{~s}\right)$ and the proton scalar relaxation contribution here is about $R_{2}{ }^{H} \cong$ $36 \mathrm{~s}^{-1}$ and $\Delta v_{1 / 2} \cong 10 \mathrm{~Hz}$. The oxygen relaxation rate is now so fast and the lifetimes of the oxygen spin states are so short that the oxygen nuclei have effectively decoupled themselves from the protons. Near the $T_{1}$ minimum the proton lines for all $-\mathrm{OH}$ protons will still be broad, but a significant part of the broadening arises from the dipolar relaxation which is most efficient at the $T_{1}$ minimum.

For the case of moderately rapid chemical exchange and very little ${ }^{17} \mathrm{O}$ enrichment the proton linewidths are still

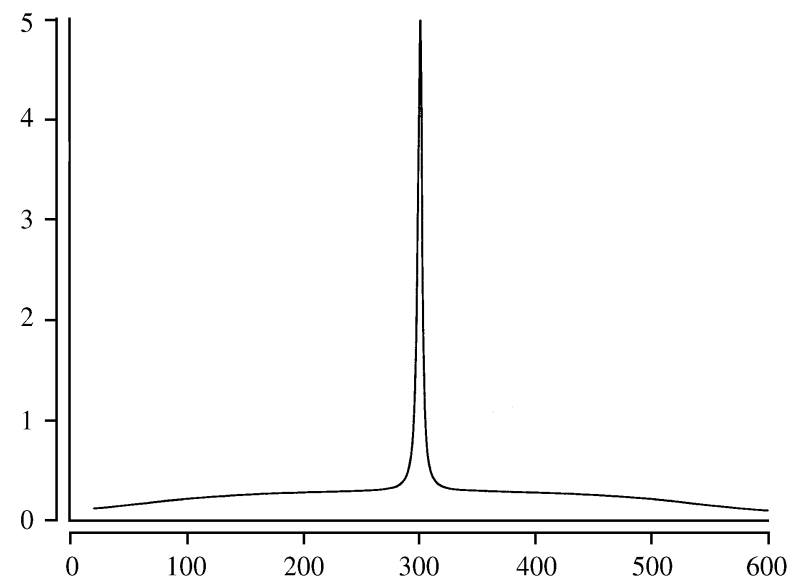

Figure 3. Simulated spectrum of the hydroxyl proton region of an $80 / 20$ mixture of $\mathrm{CH}_{3}{ }^{17} \mathrm{OH}$ and $\mathrm{CH}_{3}{ }^{16} \mathrm{OH}$. The $\mathrm{CH}_{3}{ }^{17} \mathrm{OH}$ part of the spectrum is a sextet. Each component of the sextet has a line width of $30 \mathrm{~Hz}$. The sharp line in the center arises from the $\mathrm{CH}_{3}{ }^{16} \mathrm{OH}$ component which has a line width of $0.5 \mathrm{~Hz}$.

largely determined by scalar relaxation with the oxygen. In an early elegant paper by Meiboom ${ }^{9}$ the $\mathrm{pH}$ dependence of the proton chemical exchange in water, it is clearly shown that even for ${ }^{17} \mathrm{O}$ at natural abundance levels $(0.037 \%)$, the proton $T_{2}$ value is determined by the scalar relaxation due to the small amount of oxygen-17 present. The amount of broadening is, of course, rather small because the concentration of oxygen-17 is quite small.

This same phenomenon of proton line broadening due to coupling to a quadrupolar nucleus is often seen. Protons that are spin-coupled to nitrogen-14 have linewidths that are typically several hundred Hertz wide. The narrower 
-NH proton linewidths are to be expected. Although directly bonded $\mathrm{NH}$ and $\mathrm{OH}$ spin coupling constants are comparable, the nitrogen relaxation times are much longer. The result is that the proton line broadening is typically less severe.

\section{Summary}

Hydroxyl proton spin-spin relaxation times, $R_{2}{ }^{H}$ and, consequently, the ${ }^{17} \mathrm{OH}$ proton linewidths are related to three different processes: dipolar relaxation, chemical exchange broadening and scalar relaxation via $\mathrm{O}-17$ spin coupling. At high temperatures or in acidified samples the chemical exchange of the hydroxyl protons is fast in alcohols and in water, therefore the spin coupling will be suppressed and a relatively narrow resonance line will be seen. In this situation, ${ }^{17} \mathrm{O}$ enrichment studies should provide reliable information about the $\mathrm{OH}$ intramolecular correlation time. For pure samples in which the $\mathrm{OH}$ exchange is slow, scalar relaxation caused by J-coupling with rapidly relaxing O-17 nucleus can cause the hydroxyl ${ }^{17} \mathrm{OH}$ line to disappear into the noise and the only hydroxyl proton signal observed in a mixture of $\mathrm{R}^{17} \mathrm{OH}$ and $\mathrm{R}^{16} \mathrm{OH}$ will be that from the $\mathrm{R}^{16} \mathrm{OH}$ molecules. Failure to recognize this situation will lead to significant systematic errors in relaxation time experiments. In light of these complications, we have measured the correlation times in methanol using a newly developed method ${ }^{11}$. The results of the new experiments show the expected behavior for the temperature and concentration dependence of $\chi_{D}$ for the OD deuteron in neat methanol ${ }^{12}$ and in binary mixtures of methanol and carbon tetrachloride ${ }^{11}$.

\section{Acknowledgment}

We thank the National Science Foundation, grant number CHE-9500735 for the support of this research. We thank T.D. Ferris for the O-17 spectral data.

\section{References}

1. Ludwig, R.; Zeidler, M.D. Mol. Phys. 1994, 82, 213.

2. Ludwig, R.; Gill, D.S.; Zeidler, M.D. Z. Naturrforsch. 1990, $46 a, 89$.

3. van der Maarel, J.R.C.; Lankhorst, D.; de Bleijser, J.; Leyte, J.C. Chem. Phys. Lett. 1985, 122, 541.

4. Lankhorst, D.; Schriever, J.; Leyte, J.C. Ber. Bunsenges. Phys. Chem. 1982, 86, 215.

5. van der Maarel, J.R.C.; Lankhorst, D.; de Bleijser, J.; Leyte, J.C. J. Phys. Chem. 1986, 90, 1470.

6. Gordalla, B. C.; Zeidler, M.D. Mol. Phys. 1986, 59, 817.

7.Ludwig, R.; Zeidler, M.D.; Farrar, T.C. Z. Naturforsch. 1994, 49a, 1131.

8. Wendt, M.A.; Meiler, J.; Weinhold, F.; Farrar, T.C. Molec. Phys. 1998, 93, 145.

9. Meiboom, S. J. Chem. Phys. 1961, 34, 375; see also Meiboom, S.; Luz, Z.; Gill, D. J. chem. Phys. 1957, 27, 1411.

10. Farrar, T.C. An Introduction to Pulse NMR Spectroscopy, 3rd edition; The Farragut Press; Madison, 1998.

11. Wendt, M.A.; Farrar, T.C. Molec. Phys. 1999, 95, 1077.

12. Wendt, M.A.; Zeidler, M.D.; Farrar, T.C. in press Molec. Phys. 